Check for updates

Cite this: RSC Adv., 2018, 8, 9812

\title{
A pH and magnetic dual-response hydrogel for synergistic chemo-magnetic hyperthermia tumor therapy $\dagger$
}

\author{
Xiaohan Zhou, ${ }^{\text {a }}$ Longchen Wang, ${ }^{\mathrm{b}}$ Yanjun $\mathrm{Xu},{ }^{\mathrm{b}}$ Wenxian Du, ${ }^{\mathrm{c}}$ Xiaojun Cai, ${ }^{\mathrm{b}}$ \\ Fengjuan Wang, ${ }^{a}$ Yi Ling, ${ }^{b}$ Hangrong Chen, (D) ${ }^{c}$ Zhigang Wang, ${ }^{a}$ Bing $\mathrm{Hu}^{* b}$ \\ and Yuanyi Zheng $\mathbb{D}$ *ab
}

To overcome the toxicity of chemotherapy, increasing attention has been paid to local drug delivery systems (DDSs). pH-Sensitive hydrogels have emerged as promising DDS materials in the biomedical field due to their remarkable characteristics. However, the $\mathrm{pH}$ environment in tumor varies from person to person, which makes the applicability of systems based on $\mathrm{pH}$ challenging. In this study, we developed a contractible hydroxypropyl methyl cellulose $(\mathrm{HPMC}) / \mathrm{Fe}_{3} \mathrm{O}_{4}$ hydrogel with dual-response $\mathrm{pH}$ and magnetic properties aiming to overcome the limitations of $\mathrm{pH}$-sensitive hydrogel drug delivery systems and further increase their efficiency in tumor therapy. The $\mathrm{HPMC} / \mathrm{Fe}_{3} \mathrm{O}_{4}$ hydrogel could act as a drug delivery system that combines $\mathrm{pH}$-sensitive triggering and magnetic dual-response drug release for synergistic chemo-magnetic hyperthermia therapy. The drug delivery profile of the $\mathrm{HPMC} / \mathrm{Fe}_{3} \mathrm{O}_{4} /$ doxorubicin hydrochloride (DOX) hydrogel was determined in vitro and revealed a remarkable $\mathrm{pH}$ sensitive performance. After synergistic chemo-magnetic hyperthermia treatment, mice with 4T1 breast cancer xenografts recovered without any recurrence or metastasis, demonstrating the synergistic effect of chemotherapy and magnetic hyperthermia therapy. Meanwhile, reduced toxicity and superior anticancer effects were achieved due to the combined effect of the $\mathrm{pH}$ and magnetic hyperthermia response properties. This study demonstrated the high efficacy and low toxicity of the improved design of $\mathrm{HPMC} / \mathrm{Fe}_{3} \mathrm{O}_{4}$ for drug delivery, which may provide a promising approach for the application of chemo-magnetic hyperthermia cancer therapy.

Received 8th January 2018

Accepted 2nd March 2018

DOI: $10.1039 / c 8 r a 00215 k$

rsc.li/rsc-advances

\section{Introduction}

Many efforts have been made over the past few decades to improve the available treatment options for cancer, but, to date, chemotherapy remains one of the most common approaches., However, traditionally available anticancer drugs frequently cause severe systemic side effects due to a lack of ability to differentiate cancer cells from normal cells. The toxicity of chemotherapy drugs and the compliance of patients limit the dose that can be delivered, leading to a reduction in the therapeutic efficacy. ${ }^{3-5}$ To overcome these drawbacks, increasing

${ }^{a}$ Chongqing Key Laboratory of Ultrasound Molecular Imaging, State Key Laboratory of Ultrasound Engineering in Medicine Co-Founded by Chongqing, The Ministry of Science and Technology, Second Affiliated Hospital of Chongqing Medical University, Chongqing, 400010, PR China.E-mail: zhengyuanyi@163.com

${ }^{b}$ Shanghai Jiao Tong University Affiliated Sixth People's Hospital, Shanghai, 200233, PR China

${ }^{c}$ State Key Laboratory of High Performance Ceramic and Superfine Microstructures, Shanghai Institute of Ceramics, Chinese Academy of Sciences, Shanghai, 200050, PR China

$\dagger$ Electronic supplementary information (ESI) available. See DOI: 10.1039/c8ra00215k attention has been paid to local drug delivery systems (DDSs). Hydrogels, which are hydrophilic polymers swollen by water, ${ }^{6}$ have emerged as promising DDS materials in the biomedical field $^{7}$ due to their remarkable characteristics, such as their high biocompatibility, fabrication versatility, and similarity to the native extracellular matrix. In recent years, hydrogels employing newly developed polymers that respond to $\mathrm{pH}$, temperature, light and electric fields, inducing on-demand or environmentally specific release kinetics, have achieved significant progress as drug delivery systems. ${ }^{8}$ Among these characteristics, the ability to respond to $\mathrm{pH}$ has attracted increasing attention. It is well known that one of the internal biological features of solid tumor microenvironments is acidosis. ${ }^{9}$ It has been demonstrated that the extracellular tumor $\mathrm{pH}$ values are between $\mathrm{pH} 5$ and 7 because of the high rate of glycolysis in the bloodstream. ${ }^{\mathbf{1 0 , 1 1}}$ Moreover, endosomes and lysosomes inside tumor cells exhibit much lower $\mathrm{pH}$ values, in the range of $\mathrm{pH} 4.5-5.5 .^{12,13}$

Thus, pH-sensitive hydrogels may be appropriate biomaterials for drug release in situ to achieve drug release only in the tumor and to minimize drug leakage to normal tissue. However, pH-sensitive hydrogels have some limitations. For example, release is triggered by the acidic tumor microenvironment and 
the $\mathrm{pH}$ may vary from person to person, which makes the applicability of systems based on $\mathrm{pH}$ challenging. ${ }^{14}$ It is also well known that some hydrogels respond to temperature.,15 Therefore, finding a $\mathrm{pH}$ and temperature dual-response hydrogel and changing the temperature to enhance the drug release might improve the results based on individual differences.

There are many strategies to change the local temperature of a tumor, such as hyperthermia ablation, a tumor therapy strategy that produces heat that contributes to tumor ablation. ${ }^{16}$ Among hyperthermia ablation strategies, magnetic hyperthermia treatment is a technique by which magnetic nanoparticles absorb energy from a magnetic field and convert the electromagnetic energy to heat, resulting in tumor ablation. ${ }^{17,18}$ Recently, an injectable and contractible hydroxypropyl methylcellulose (HPMC) $/ \mathrm{Fe}_{3} \mathrm{O}_{4}$ hydrogel has been developed for magnetic hyperthermia treatment of tumors in vivo, ${ }^{19}$ which has many advantages. First, the high water content of the $\mathrm{HPMC} / \mathrm{Fe}_{3} \mathrm{O}_{4}$ hydrogel contributes to its biocompatibility, ${ }^{20}$ Second, the HPMC/ $\mathrm{Fe}_{3} \mathrm{O}_{4}$ hydrogel has a high thermal response, so its magnetic hydrothermal effects may enhance its drug delivery. ${ }^{16,21,22}$ Third, in a previous study, we found that the $\mathrm{HPMC} / \mathrm{Fe}_{3} \mathrm{O}_{4}$ hydrogel is $\mathrm{pH}$-sensitive, which is quite appropriate for the acidic tumor microenvironment, indicating it may be a good drug delivery system for the selective release of antineoplastic drugs, without hurting normal tissues. Finally, the $\mathrm{HPMC} / \mathrm{Fe}_{3} \mathrm{O}_{4}$ hydrogel is safe for medical use, since all the contents of this hydrogel have been used in clinical applications or in the biomedical field. ${ }^{23-29}$

However, the pure $\mathrm{HPMC} / \mathrm{Fe}_{3} \mathrm{O}_{4}$ hydrogel still has some limitations in tumor therapy. It has been reported that after a heat shock, all cell types show increased thermoresistance and the required temperatures could not be achieved effectively under clinical conditions. ${ }^{30}$ Additionally, the increasing temperature required by hyperthermia may be followed by aggravated pain, which may reduce the compliance of patients, limiting the therapeutic efficacy.

Based on consideration of the above limitations and studies that have shown that hyperthermia temperatures can provoke an increase in the tumor blood flow and make cells more sensitive to chemotherapy for increased drug delivery by higher perfusion, ${ }^{31,32}$ we thought that the $\mathrm{HPMC} / \mathrm{Fe}_{3} \mathrm{O}_{4}$ hydrogel might provide an ideal strategy for the synergistic chemotherapeutic and magnetic hyperthermia treatment of tumors.

In this study, we investigated the drug delivery profile of the $\mathrm{HPMC} / \mathrm{Fe}_{3} \mathrm{O}_{4} /$ doxorubicin hydrochloride (DOX) hydrogel in vitro and its therapeutic efficiency for synergistic magnetic hyperthermia treatment in vivo (Scheme 1). Furthermore, we employed spherical $\mathrm{Fe}_{3} \mathrm{O}_{4}$ particles instead of $\mathrm{Fe}_{3} \mathrm{O}_{4}$ nanoparticles to further improve the dispersibility of the $\mathrm{Fe}_{3} \mathrm{O}_{4}$ particles in the hydrogel, resulting in higher safety at increasing temperatures, enabling further clinical applications.

\section{Experimental section}

\subsection{Preparation of spherical $\mathrm{Fe}_{3} \mathrm{O}_{4}$ and synthesis of HPMC/ $\mathrm{Fe}_{3} \mathrm{O}_{4}$ hydrogel}

$\mathrm{Fe}_{3} \mathrm{O}_{4}$ spheres were prepared via a modified solvothermal reaction. $^{33} 1.350 \mathrm{~g}$ of iron(III) chloride hexahydrate (Sigma-

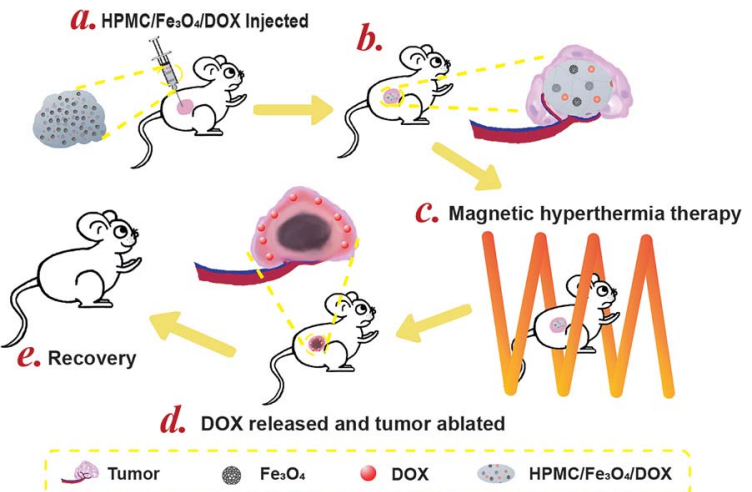

Scheme $1 \mathrm{pH}$-Sensitive and magnetic response $\mathrm{HPMC} / \mathrm{Fe}_{3} \mathrm{O}_{4} / \mathrm{DOX}$ for chemo-thermal tumor therapy. (a) $\mathrm{HPMC} / \mathrm{Fe}_{3} \mathrm{O}_{4} / \mathrm{DOX}$ was injected into the mouse tumor. (b) The injected hydrogel was in the center of the tumor. (c) The mouse with the tumor injected with $\mathrm{HPMC} / \mathrm{Fe}_{3} \mathrm{O}_{4} /$ DOX was placed in the middle of a coil for magnetic hyperthermia therapy. (d) After magnetic hyperthermia therapy, DOX was released from the hydrogel and the tumor area around the hydrogel was ablated. (e) After the magnetic hyperthermia treatment, the health of the mouse recovered.

Aldrich Co. LLC. USA CAS: 10 025-77-1) and $3.854 \mathrm{~g}$ of ammonium acetate (Sinopharm Chemical Reagent Co., Ltd China CAS: 631-61-8) were dispersed in $70 \mathrm{~mL}$ of ethylene glycol (Sinopharm Chemical Reagent Co., Ltd China CAS: 107-21-1) to homogeneity. Then, the solution was transferred into a hydrothermal reactor and heated to $200{ }^{\circ} \mathrm{C}$ for $16.5 \mathrm{~h}$. After cooling to room temperature, the black $\mathrm{Fe}_{3} \mathrm{O}_{4}$ spheres were washed with ethanol using an ultrasonic cleaner. All the $\mathrm{Fe}_{3} \mathrm{O}_{4}$ spheres were collected by centrifugation and lyophilized to store. The HPMC/ $\mathrm{Fe}_{3} \mathrm{O}_{4}$ hydrogel was synthesized by following the reported method. ${ }^{19}$ Four components were used to prepare the thermally responsive $\mathrm{HPMC} / \mathrm{Fe}_{3} \mathrm{O}_{4}$ hydrogel: $\mathrm{Fe}_{3} \mathrm{O}_{4}$ spheres, hydroxypropyl methyl cellulose (HPMC, Sigma-Aldrich Co. LLC. USA CAS: 9004-65-3) and polyvinyl alcohol (PVA, fully hydrolyzed; Sigma-Aldrich Co. LLC. USA CAS: 9002-89-5). $0.087 \mathrm{~g}$ of $\mathrm{Fe}_{3} \mathrm{O}_{4}$ spheres and $0.163 \mathrm{~g}$ of HPMC were mixed in a beaker, then placed in an orbital shaker incubator $\left(37.0^{\circ} \mathrm{C}, 120 \mathrm{rpm}, 24 \mathrm{~h}\right)$ until totally blended. The DOX and PBS solutions were sterile when purchased. Before the preparation of the hydrogel, UV irradiation was used to sterilize all the components of the hydrogel for $30 \mathrm{~min}$. Then, the hydrogel was prepared on a laminar flow bench. PVA was dissolved in axenic PBS at a solid-liquid (S/L) ratio of 0.04 and doxorubicin hydrochloride (J\&K Scientific Co., Ltd., China CAS: 25 316-40-9) was dissolved in the axenic PVA solution at a concentration of $3 \mathrm{mg} \mathrm{mL}^{-1}$. The final solution was stored in the dark at $4{ }^{\circ} \mathrm{C}$. The prepared $\mathrm{HPMC} / \mathrm{Fe}_{3} \mathrm{O}_{4}$ was mixed thoroughly with the PVA/Dox solution to synthesize the HPMC/Fe ${ }_{3} \mathrm{O}_{4}$ hydrogel loaded with Dox. $1 \mathrm{~mL}$ of the final hydrogel contains $0.087 \mathrm{~g} \mathrm{Fe}_{3} \mathrm{O}_{4}, 0.163 \mathrm{~g}$ HPMC, $0.04 \mathrm{~g}$ PVA, $0.003 \mathrm{~g}$ DOX and $1 \mathrm{~mL}$ of a PBS solution.

\subsection{Characterization}

2.2.1. Morphological and structural analysis. The morphology of the $\mathrm{Fe}_{3} \mathrm{O}_{4}$ spheres was observed by TEM imaging 
(JEOL Japan Electronics Co., Ltd, JEM-2100F) and the morphology of the HPMC/ $\mathrm{Fe}_{3} \mathrm{O}_{4}$ hydrogel was observed by SEM imaging. To prepare samples for TEM, appropriate amounts of particles were suspended in ethanol and loaded onto a copper grid for observation. The samples for SEM were dried at $37^{\circ} \mathrm{C}$ in an oven overnight while compressed with glass slides to make the surface smooth.

2.2.2. Thermogravimetric analysis. The amounts of inorganic and organic phases of the $\mathrm{HPMC} / \mathrm{Fe}_{3} \mathrm{O}_{4}$ hydrogel before and after AMF (alternating magnetic field) were measured using Thermogravimetric Analysis (NETZSCH STA 449C).

2.2.3. Swelling capacity. $60 \mu \mathrm{L}$ of the $\mathrm{HPMC} / \mathrm{Fe}_{3} \mathrm{O}_{4}$ or $\mathrm{HPMC} / \mathrm{Fe}_{3} \mathrm{O}_{4} / \mathrm{DOX}$ hydrogel was set in the center of a $25 \mathrm{~mL}$ beaker with $10 \mathrm{~mL}$ fetal bovine serum or normal saline. Each sample was weighed at $0 \mathrm{~h}$ and $24 \mathrm{~h}$. The swelling capacity ratio was calculated with the formula $R=W_{24} / W_{0}$, where $W_{24}$ is the weight of the hydrogel at $24 \mathrm{~h}$ and $W_{0}$ is the weight of the hydrogel at $0 \mathrm{~h}$.

2.2.4. Rheological properties. The proper amount of injectable $\mathrm{HPMC} / \mathrm{Fe}_{3} \mathrm{O}_{4}$ hydrogel was set on the plate of an RS150 rheometer (Thermo-Haake, Germany) with a $20 \mathrm{~mm}$ parallel plate ( $\mathrm{Ti}$, gap $0.3 \mathrm{~mm}$ ) at $22 \pm 1{ }^{\circ} \mathrm{C}$. The shearing rate used was from 0 to 1000 per minute. The interfacial shear viscosity and shear stress were recorded by the instrument.

\subsection{Heating efficiency of the $\mathrm{HPMC} / \mathrm{Fe}_{3} \mathrm{O}_{4}$ hydrogel}

$\mathrm{HPMC} / \mathrm{Fe}_{3} \mathrm{O}_{4}$ hydrogels with different concentrations of $\mathrm{Fe}_{3} \mathrm{O}_{4}$ spheres were placed in the center of the coil. An AMF was induced using a custom-built magnetic hyperthermia machine (frequency: $400 \mathrm{kHz}$; output power: $7.2 \mathrm{kw}$, coil diameter: $10 \mathrm{~cm}$ ). An infrared thermal imaging instrument (Fortric Technology, Fortric225) was used to acquire the real-time temperature on the surface. All the images captured by infrared thermography were analyzed using the FOTRIC AnalyzIR software. The longest and shortest diameters of the $\mathrm{HPMC} / \mathrm{Fe}_{3} \mathrm{O}_{4}$ in the $\mathrm{AMF}$ were measured using Vernier calipers to calculate the volume to estimate the change in volume of the hydrogel in the AMF at different times. The formula used to calculate the volume is $V=D_{\mathrm{L}} D_{\mathrm{S}}{ }^{2} / 2,{ }^{34,35}$ where $D_{\mathrm{L}}$ is the longest diameter and $D_{\mathrm{S}}$ is the shortest diameter of the tumor measured by a Vernier caliper.

\subsection{In vitro drug release}

To investigate the DOX release in vitro, $60 \mu \mathrm{L}$ of $\mathrm{HPMC} / \mathrm{Fe}_{3} \mathrm{O}_{4} /$ DOX was place in a dialysis bag (8000-14000) with $940 \mu \mathrm{L}$ phosphate buffered saline (PBS) at $\mathrm{pH} 5.5$ or $\mathrm{pH}$ 7.4. Then, the whole dialysis bag was placed in a $50 \mathrm{~mL}$ centrifuge tube with $29 \mathrm{~mL}$ PBS added afterwards. The centrifuge tube was transferred to an incubated shaker to perform the release at $37{ }^{\circ} \mathrm{C}$ and $120 \mathrm{rpm}$. At $0.5 \mathrm{~h}, 1 \mathrm{~h}, 2 \mathrm{~h}, 4 \mathrm{~h}, 6 \mathrm{~h}, 8 \mathrm{~h}, 10 \mathrm{~h}, 12 \mathrm{~h}$, and $24 \mathrm{~h}$, $1 \mathrm{~mL}$ samples were taken from the tube and an additional $1 \mathrm{~mL}$ of pure PBS was added to maintain the medium volume. The tubes in the experimental group were exposed to AMF in the center of the coil for $1 \mathrm{~min}$ at $1 \mathrm{~h}, 4 \mathrm{~h}, 8 \mathrm{~h}$, and $12 \mathrm{~h}$. To investigate the efficiency of the DOX release, all the samples were measured using a UV-Vis spectrometer (Shimadzu UV3600, Japan). The cumulative amount of DOX released from the $\mathrm{HPMC} / \mathrm{Fe}_{3} \mathrm{O}_{4}$ hydrogel with time was calculated. As a control, the DOX release without AMF exposure was performed using the same method.

\subsection{In vitro and in vivo biosafety}

Human umbilical vein endothelial cells (HUVEC) were from Chongqing Medical University and cultivated in 96-well plates (number of cells per orifice, approximately $1 \times 10^{4}$ ) in an

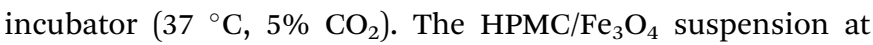
concentrations of $100 \mu \mathrm{g} \mathrm{mL} \mathrm{m}^{-1}, 200 \mu \mathrm{g} \mathrm{mL} \mathrm{m}^{-1}, 300 \mu \mathrm{g} \mathrm{mL} \mathrm{mL}^{-1}$, $400 \mu \mathrm{g} \mathrm{mL} \mathrm{g}^{-1}, 500 \mu \mathrm{g} \mathrm{mL}{ }^{-1}, 600 \mu \mathrm{g} \mathrm{mL}^{-1}, 700 \mu \mathrm{g} \mathrm{mL}{ }^{-1}$ and $800 \mu \mathrm{g} \mathrm{mL}{ }^{-1}$ were sterilized using ultraviolet light. After culturing for $24 \mathrm{~h}, 100 \mu \mathrm{L}$ of the prepared suspension at different concentrations was added in the experimental group. After incubating with the suspension for $24 \mathrm{~h}$, the 96-well plates were rinsed with PBS and the previous medium was replaced with Dulbecco's modified eagle medium (DMEM) with $10 \mu \mathrm{L}$ of cellcounting kit-8 solution (DOJINDO Molecular Technologies, INC.) for the experimental group. No $\mathrm{HPMC} / \mathrm{Fe}_{3} \mathrm{O}_{4}$ suspension was added to the DMEM for the cell culture in the control group. For the blank group, there were no cells or $\mathrm{HPMC} / \mathrm{Fe}_{3} \mathrm{O}_{4}$ suspension. After incubating for an additional $0.5 \mathrm{~h}$, a microplate reader was used to detect the absorbance of each sample with an optical filter at $450 \mathrm{~nm}$. The cell inhibition rate was calculated using the formula $R=\left(\mathrm{OD}_{\mathrm{s}}-\mathrm{OD}_{\mathrm{b}}\right) /\left(\mathrm{OD}_{\mathrm{c}}-\mathrm{OD}_{\mathrm{b}}\right)$, where $\mathrm{OD}_{\mathrm{c}}, \mathrm{OD}_{\mathrm{s}}$ and $\mathrm{OD}_{\mathrm{b}}$ represent the optical density values of the control group, the experimental group and the blank group, respectively.

The safety of $\mathrm{HPMC} / \mathrm{Fe}_{3} \mathrm{O}_{4}$ in vivo was evaluated using biochemical assays of mice serum at different dosages (1, 2, and $4 \mathrm{mg} \mathrm{kg}^{-1}$ ) of the $\mathrm{HPMC} / \mathrm{Fe}_{3} \mathrm{O}_{4}$ suspension. The suspension was injected into a vein and blood samples were taken at different time points ( 7 and 14 days). To reflect the liver and renal functions, some serum biochemical indicators were detected including total protein (TP), alkaline phosphatase (ALP), aspartate aminotransferase (AST), alanine aminotransferase (ALT), albumin (ALB), blood urea nitrogen (BUN) and serum creatinine ( $\mathrm{sCr}$ ). The serum of the mice was analyzed using an automated biochemical analyzer (Rayto chemray 240, China).

\subsection{Ablation efficiency in excised bovine liver}

Different volumes $\left(40,60\right.$ and $80 \mu \mathrm{L}$ ) of $\mathrm{HPMC} / \mathrm{Fe}_{3} \mathrm{O}_{4}$ were injected into prepared excised bovine liver under ultrasound guiding and then exposed to AMF for different time periods (3, 5, 7 and $10 \mathrm{~min})$. Additionally, the volumes of $\mathrm{HPMC} / \mathrm{Fe}_{3} \mathrm{O}_{4}$ were measured by ultrasound. Otherwise, elastography was used to detect rigidity changes in the $\mathrm{HPMC} / \mathrm{Fe}_{3} \mathrm{O}_{4}$ hydrogel after AMF ablation. The ablation distance of the bovine liver was macroscopically measured from the border of the implant to the edge of the necrotic area.

\subsection{The nude mouse $4 \mathrm{~T} 1$ mouse breast cancer xenograft model}

The 4T1 mouse breast cancer cell line was purchased from the Type Culture Collection of the Chinese Academy of Sciences, Shanghai, China and cultured following the guidance with purchase. The cells were collected by digestion, centrifugation 
and dispersed in axenic PBS at the concentration of $1 \times 10^{7}$ cell per $0.1 \mathrm{~mL}$. 40 female SPF nude mice at a mean weight of $20 \pm$ $0.3 \mathrm{~g}$ were injected with $0.1 \mathrm{~mL}$ of $4 \mathrm{~T} 1$ cell suspension per mouse in the back near the right hind leg. All the animal experiments were approved by the Animal Welfare Ethics Committee of the Shanghai Sixth People's Hospital.

\subsection{In vivo therapeutic efficiency}

The HPMC/ $/ \mathrm{Fe}_{3} \mathrm{O}_{4} /$ DOX hydrogel was injected into anesthetized mice in the center of the tumor in situ under the guidance of real-time ultrasound. A far-infrared thermometer (Fortric Technology, Fortric225) was applied to monitor the peak surface temperature of the tumors continuously. Moreover, the tumor volumes and the weight of mice were macroscopically measured each day. The tumor volumes were estimated using the formula $V=D_{\mathrm{L}} D_{\mathrm{S}}{ }^{2} / 2$. After the magnetic hyperthermia treatment, all the mice were fed to observe their health status and the recurrence of the tumors and then euthanized. Two of each group were randomly chosen to be dissected to obtain the heart, liver, spleen, lung and kidney for hematoxylin and eosin staining (H\&E staining) to observe the difference between the normal nude mice and the tumor-bearing mice. The survival ratio of the tumor-bearing mice was calculated using the formula $R_{\mathrm{S}}=N_{\mathrm{S}} / N_{\mathrm{t}}$, where $N_{\mathrm{s}}$ is the number of mice that survived and $N_{\mathrm{t}}$ is the total number of mice. In addition, the tumor inhibition ratio of chemo-thermal therapy was calculated using the formula $R_{\text {inhibition }}=\left(1-r_{\text {chemo }} \times r_{\text {thermal }}\right) \times 100 \%$, $r_{\text {treatment }}=V_{\text {treatment }} / V_{\text {control }} \times 100 \%$, where $r$ is the relative tumor growth rate after treatment and $V$ is the relative tumor volume. ${ }^{36,37}$

\subsection{Statistical analysis}

Statistical analysis was performed using the Origin 9.0 software (OriginLab Corporation, Northampton, Massachusetts, USA). All values are expressed as the mean \pm standard deviation, except for the calculated ratio and mechanical test. At the level $a=0.05$, significance was established for all of the significance tests.

\section{Results and discussion}

\subsection{Synthesis and Characterization}

To investigate the heating efficiency of different concentrations of $\mathrm{Fe}_{3} \mathrm{O}_{4}$ spheres in the hydrogel in alternating magnetic fields, five concentrations of $\mathrm{Fe}_{3} \mathrm{O}_{4}$ spheres, from $0 \%$ to $40 \%$ with the corresponding different concentrations hydroxypropyl methyl cellulose (HPMC), were prepared. Additionally, $\mathrm{Fe}_{3} \mathrm{O}_{4}$ nanoparticles were used to prepare another $\mathrm{HPMC} / \mathrm{Fe}_{3} \mathrm{O}_{4}$ hydrogel to compare the heating efficiency of $\mathrm{Fe}_{3} \mathrm{O}_{4}$ spheres and $\mathrm{Fe}_{3} \mathrm{O}_{4}$ nanoparticles. As shown in the TEM and SEM images of the sample (Fig. 1a-d), uniform $\mathrm{Fe}_{3} \mathrm{O}_{4}$ spheres were formed. The rough surface of the spheres indicates that the spheres are made up of $\mathrm{Fe}_{3} \mathrm{O}_{4}$ grains. ${ }^{38}$ The average diameter of the spheres obtained from the TEM and SEM images was $200 \pm 26 \mathrm{~nm}$. To observe the dispersity of the two types of $\mathrm{Fe}_{3} \mathrm{O}_{4}$, the samples were made from $\mathrm{Fe}_{3} \mathrm{O}_{4}$ nanoparticles and $\mathrm{Fe}_{3} \mathrm{O}_{4}$ spheres,
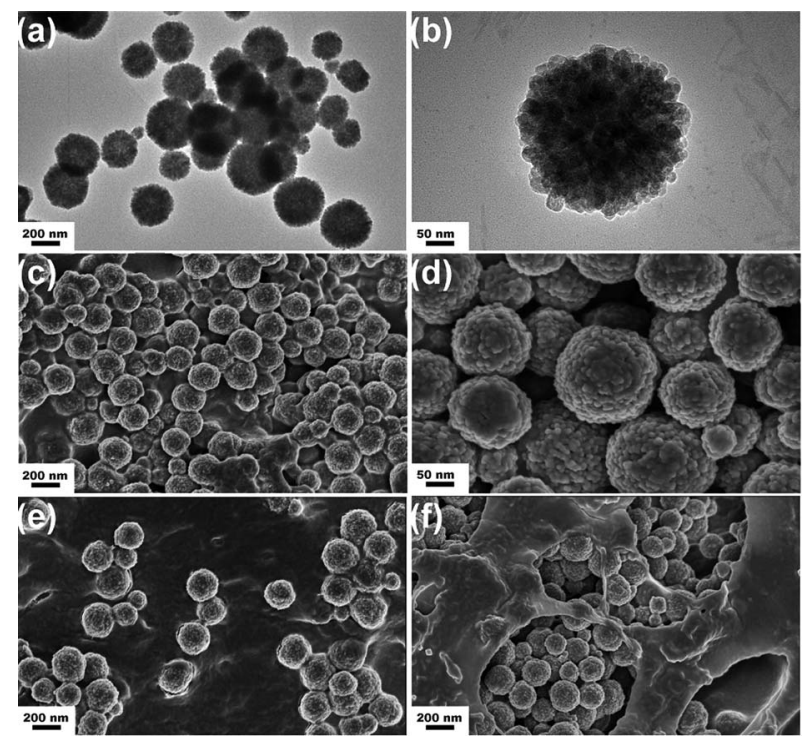

Fig. 1 TEM and SEM images of uniform spheres of $\mathrm{Fe}_{3} \mathrm{O}_{4}$. (a) Typical TEM image of $\mathrm{Fe}_{3} \mathrm{O}_{4}$. (b) Detailed TEM image of $\mathrm{Fe}_{3} \mathrm{O}_{4}$ spheres showing the grains gathering into a sphere. (c) Typical SEM image of uniform spheres of $\mathrm{Fe}_{3} \mathrm{O}_{4}$. (d) Detailed $\mathrm{SEM}$ image of $\mathrm{Fe}_{3} \mathrm{O}_{4}$ spheres showing the rough surface. (e) $\mathrm{Fe}_{3} \mathrm{O}_{4}$ spheres dispersed homogeneously in $\mathrm{HPMC} / \mathrm{Fe}_{3} \mathrm{O}_{4}$ before exposure to the alternating magnetic field (AMF). (f) $\mathrm{Fe}_{3} \mathrm{O}_{4}$ spheres gathered after exposure to the AMF, with retention of the rough surface.

respectively. The SEM images of the two samples revealed that the $\mathrm{Fe}_{3} \mathrm{O}_{4}$ sphere sample was more homogeneous than the $\mathrm{Fe}_{3} \mathrm{O}_{4}$ nanoparticles in the hydrogel (Fig. S1c $\dagger$ ). The SEM image of the samples before and after exposure to the alternating magnetic field (AMF) demonstrated that the rough surface of the $\mathrm{Fe}_{3} \mathrm{O}_{4}$ spheres was retained, so AMF did not change the structure of the $\mathrm{Fe}_{3} \mathrm{O}_{4}$ spheres. Additionally, the $\mathrm{Fe}_{3} \mathrm{O}_{4}$ spheres that were homogeneously dispersed before the AMF were gathered together after the AMF process. This may be why the temperature increased more rapidly in the latter half of the heating process, since the heating efficiency is proportional to the thermal power per unit mass for magnetic materials. ${ }^{39}$

To investigate the contents of the $\mathrm{HPMC} / \mathrm{Fe}_{3} \mathrm{O}_{4}$ hydrogel and any loss in the heating process, a thermogravimetric analysis was conducted. The thermogravimetric curves (Fig. 2a) shows that before exposure to the AMF, the $\mathrm{HPMC} / \mathrm{Fe}_{3} \mathrm{O}_{4}$ hydrogel contained $66.8 \mathrm{wt} \%$ of absorbed water, $20.8 \mathrm{wt} \%$ of organics, and $12.4 \mathrm{wt} \% \mathrm{Fe}_{3} \mathrm{O}_{4}$, whereas after exposure to the AMF the $\mathrm{HPMC} / \mathrm{Fe}_{3} \mathrm{O}_{4}$ hydrogel consisted of $48.1 \mathrm{wt} \%$ of absorbed water, $39.2 \mathrm{wt} \%$ of organics and $12.7 \mathrm{wt} \% \mathrm{Fe}_{3} \mathrm{O}_{4}$. Thus, the thermogravimetric curves indicate that the weight loss during the magnetic hyperthermia treatment is mainly due to the absorbed water. The swelling capacity ratio was determined to estimate the water absorption. Fig. 2b shows that the swelling capacity ratios of the $\mathrm{HPMC} / \mathrm{Fe}_{3} \mathrm{O}_{4} / \mathrm{DOX}$ and $\mathrm{HPMC} / \mathrm{Fe}_{3} \mathrm{O}_{4}$ hydrogels are approximately $(P>0.05)$, which demonstrates there is no significant difference between the two groups. The swelling capacity ratio of the $\mathrm{HPMC} / \mathrm{Fe}_{3} \mathrm{O}_{4}$ hydrogel in fetal bovine serum, which simulated the internal environment, showed an increase in the water content. As has been reported previously, 
(a)

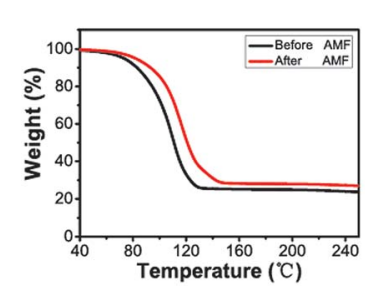

(c)

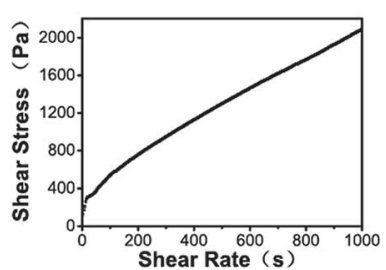

(d)

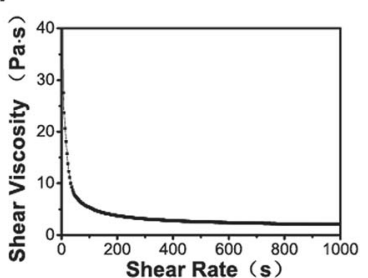

Fig. 2 (a) Thermogravimetric curves of the $\mathrm{HPMC} / \mathrm{Fe}_{3} \mathrm{O}_{4}$ hydrogel before and after exposure to an AMF for $5 \mathrm{~min}$, showing the changes in the contents of the AMF. (b) The swelling capacity ratio of the HPMC/ $\mathrm{Fe}_{3} \mathrm{O}_{4}$ hydrogel with and without DOX in fetal bovine serum, showing water absorption. (c) and (d) As shear rate increased, the shear stress increased and the shear viscosity decreased, demonstrating the $\mathrm{HPMC} / \mathrm{Fe}_{3} \mathrm{O}_{4}$ hydrogel is a pseudoplastic fluid and can be injected.

a high water content provides physical similarity to tissues and can give hydrogels excellent biocompatibility and the capability to easily encapsulate hydrophilic drugs. ${ }^{15,40,41}$ To determine whether $\mathrm{HPMC} / \mathrm{Fe}_{3} \mathrm{O}_{4}$ is injectable, its rheological properties were tested. The rheological property curve (Fig. 2c and d) shows the shear-thinning character of the HPMC/ $\mathrm{Fe}_{3} \mathrm{O}_{4}$ hydrogel. Shear-thinning hydrogels flow like low-viscosity fluids under shear stress during injection, but quickly recover their initial stiffness after the removal of shear stress in the body. ${ }^{42}$ During the injection process, the $\mathrm{HPMC} / \mathrm{Fe}_{3} \mathrm{O}_{4}$ hydrogel was injected into the body via the application of shear stress. The shear-thinning properties of the $\mathrm{HPMC} / \mathrm{Fe}_{3} \mathrm{O}_{4}$ hydrogel demonstrates that in the process of injection, as the stress strengthened, the $\mathrm{HPMC} / \mathrm{Fe}_{3} \mathrm{O}_{4}$ hydrogel gets thinner, which indicates that it can be injected into the body.

\subsection{Heating efficiency of the $\mathrm{HPMC} / \mathrm{Fe}_{3} \mathrm{O}_{4}$ hydrogel}

To select the optimal concentration of $\mathrm{Fe}_{3} \mathrm{O}_{4}$ spheres in the $\mathrm{HPMC} / \mathrm{Fe}_{3} \mathrm{O}_{4}$ hydrogel, samples with different concentrations were place in a glass culture dish at the center of the coil with a thermography recording the temperature. As shown in Fig. 3a and $b$, the temperature at the surface of the $\mathrm{HPMC} / \mathrm{Fe}_{3} \mathrm{O}_{4}$ hydrogel increased with $\mathrm{Fe}_{3} \mathrm{O}_{4}$ content and heating time. The slope of the curve shows the speed of the temperature increase. $30 \% \mathrm{Fe}_{3} \mathrm{O}_{4}$ displayed a steady increase in heating that can be easily controlled. Considering the therapeutic effect and safety, $30 \% \mathrm{Fe}_{3} \mathrm{O}_{4}$ was selected for the following experiments due its rapid and stable increase in temperature. The volume change of the $\mathrm{HPMC} / \mathrm{Fe}_{3} \mathrm{O}_{4}$ hydrogel was estimated. After exposure to an AMF for $120 \mathrm{~s}, 37 \%$ of the volume of $30 \% \mathrm{Fe}_{3} \mathrm{O}_{4}$ remained, while that of $0 \% \mathrm{Fe}_{3} \mathrm{O}_{4}$ did not change significantly. In Fig. 3c, the

(a)

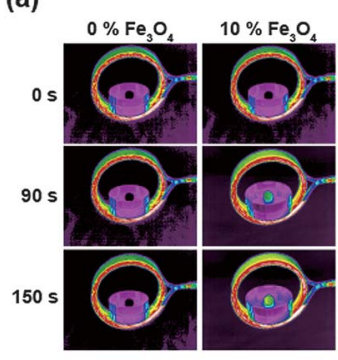

(b)

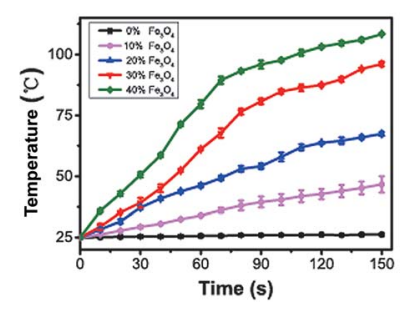

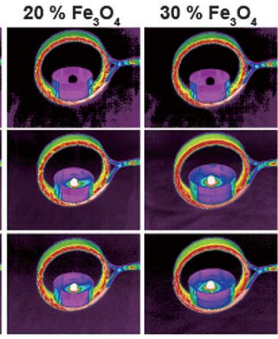

(c)
Fig. 3 (a) Thermo-images of different $\mathrm{Fe}_{3} \mathrm{O}_{4}$ particle contents in $\mathrm{HPMC} / \mathrm{Fe}_{3} \mathrm{O}_{4}$ hydrogels at different time points. (b) The heating timetemperature curves of different contents of $\mathrm{Fe}_{3} \mathrm{O}_{4}$ particles in $\mathrm{HPMC} /$ $\mathrm{Fe}_{3} \mathrm{O}_{4}$ hydrogels. (c) The volume loss of $\mathrm{HPMC} / \mathrm{Fe}_{3} \mathrm{O}_{4}$ hydrogels with and without $30 \% \mathrm{Fe}_{3} \mathrm{O}_{4}$ in the AMF.

volume of the $30 \% \mathrm{Fe}_{3} \mathrm{O}_{4}$ in $\mathrm{HPMC} / \mathrm{Fe}_{3} \mathrm{O}_{4}$ changes while there is little change in the HPMC hydrogel, indicated that the heat generated by the coil itself is not the main cause of the shrinking of the hydrogel. Instead, the heat produced by the $\mathrm{Fe}_{3} \mathrm{O}_{4}$ spheres in the AMF results in the loss of volume. Since $\mathrm{Fe}_{3} \mathrm{O}_{4}$ spheres were used in $\mathrm{HPMC} / \mathrm{Fe}_{3} \mathrm{O}_{4}$, the relative heating efficiencies of $\mathrm{Fe}_{3} \mathrm{O}_{4}$ nanoparticles and $\mathrm{Fe}_{3} \mathrm{O}_{4}$ spheres were measured. The temperature increases for $\mathrm{Fe}_{3} \mathrm{O}_{4}$ spheres in the hydrogel and for $\mathrm{Fe}_{3} \mathrm{O}_{4}$ nanoparticles showed no significant difference (Fig. S1a and $\mathrm{b} \dagger$ ). Different volumes (40, 60, and $80 \mu \mathrm{L}$ ) of the $\mathrm{HPMC} / \mathrm{Fe}_{3} \mathrm{O}_{4}$ hydrogel were heated in the AMF. In Fig. S1d, $\dagger$ it can be seen that the temperature increase is positively correlated with the volume, while there was no significant difference between the $60 \mu \mathrm{L}$ and $80 \mu \mathrm{L}$ volumes. Therefore, $60 \mu \mathrm{L}$ was tentatively selected as the volume for ablation. Further experiments are required to select the injection volume.

\subsection{In vitro drug release}

To investigate the $\mathrm{pH}$ and magnetic dual-response of the $\mathrm{HPMC} / \mathrm{Fe}_{3} \mathrm{O}_{4}$ hydrogel, four sets of conditions were tested: in PBS at pH 7.4, in PBS at pH 5.5, in PBS at pH 5.5 with exposure to the AMF and in PBS at $\mathrm{pH} 7.4$ with exposure to the AMF. UVVis spectroscopy was used to measure the absorbance of the samples over time due to DOX. The PBS at pH 5.5 group released more than the $\mathrm{PBS}$ at $\mathrm{pH} 7.4$ group without exposure to the AMF. Meanwhile, at $1 \mathrm{~h}, 4 \mathrm{~h}, 8 \mathrm{~h}$, and $12 \mathrm{~h}$, the groups with exposure to the AMF were exposed to the AMF for $1 \mathrm{~min}$. The absorbance of each sample obviously increased after exposure to the AMF. To summarize, the cumulatively released DOX was $57.6 \%$ with the AMF and $32.3 \%$ without the AMF in $24 \mathrm{~h}$ at $\mathrm{pH}$ 7.4. Meanwhile, the AMF was applied to the PBS at $\mathrm{pH} 5.5$ group. The cumulatively released DOX was $78.8 \%$ with the AMF 
and $41.7 \%$ without the AMF. Two factors contributed to the pH-response: the solubility of DOX at acidic $\mathrm{pH}$ values ${ }^{43-45}$ and the higher solubility of the HPMC/PVA hydrogel at lower $\mathrm{pH}$ values. ${ }^{46}$ At $\mathrm{pH}$ 5.5, the hydrogel starts to be soluble and aids the increased release of DOX. The trend (Fig. 4a) in the PBS at pH 5.5 with AMF group is the same as for the PBS at $\mathrm{pH} 7.4$ with AMF group. $\mathrm{HPMC} / \mathrm{Fe}_{3} \mathrm{O}_{4} / \mathrm{DOX}$ released a significant amount of DOX after being exposed to the AMF and at lower $\mathrm{pH}$, while it released little without the $\mathrm{AMF}$ and at $\mathrm{pH}$ 7.4. The corresponding digital photos of the cumulative release of DOX are shown in Fig. $4 \mathrm{~b}$. The increasing color of the tubes shows the accumulation of DOX in different environments. These results confirm that the HPMC/ $\mathrm{Fe}_{3} \mathrm{O}_{4} / \mathrm{DOX}$ hydrogel releases DOX in response to the $\mathrm{AMF}$ and the $\mathrm{pH}$. It has been previously reported by many studies that the tumor $\mathrm{pH}$ is lower than the $\mathrm{pH}$ in normal tissues. Therefore, the $\mathrm{pH}$ and magnetic hyperthermia response release behavior triggers the release of the therapeutic anti-cancer drug, DOX, in the acidic tumor microenvironment with little release in neutral environments.

\subsection{In vitro and vivo biosafety}

Human umbilical vein endothelial cells (HUVEC) were cultured to estimate the cell viability via cell count-kit 8 (CCK8). This is a common cell detection method that is often used to assess cytotoxicity in drug testing. As shown in Fig. 5a, the cell viability was $97.0 \pm 1.6 \%$ in the control group while the value in the $800 \mu \mathrm{g} \mathrm{mL} \mathrm{m}^{-1}$ group was $81.9 \pm 3.3 \%$. The cell experiment indicates that the $\mathrm{HPMC} / \mathrm{Fe}_{3} \mathrm{O}_{4}$ hydrogel has no significant toxic effects on HUVECs. The serum biochemical indexes of mice were detected at different dosages $\left(0,1,2\right.$, and $\left.4 \mathrm{mg} \mathrm{kg}^{-1}\right)$ and different time points ( 7 and 14 days). The indicators of liver and renal function, including TP, ALP, AST, ALT, ALB, LDH, BUN, and $\mathrm{sCr}$, reveal no significant statistic differences $(P>0.05)$ compared with the control group at 7 days and 14 days after injection (Fig. 6). The heart, liver, spleen, lung, and kidney of each mouse were prepared for hematoxylin and eosin staining (H\&E staining) to observe their cells (Fig. S2† and 5b). No differences between the experimental group and the control group were observed. The experiments in vitro and in vivo demonstrate the high biological safety of the $\mathrm{HPMC} / \mathrm{Fe}_{3} \mathrm{O}_{4}$ hydrogel. (a)

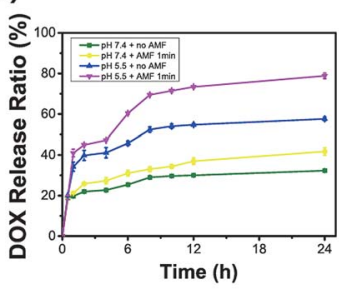

(b)

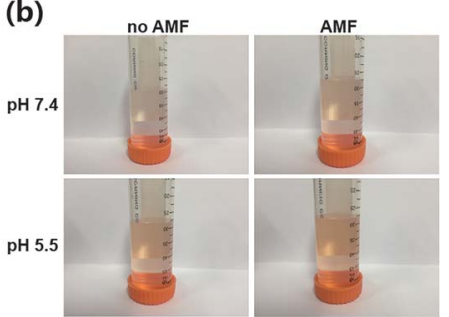

Fig. 4 (a) In vitro release profiles of $\mathrm{HPMC} / \mathrm{Fe}_{3} \mathrm{O}_{4} / \mathrm{DOX}$ at different $\mathrm{pH}$ values ( $\mathrm{pH} 7.4$ and $\mathrm{pH} 5.5$ ) with or without the AMF, showing that DOX was released at $\mathrm{pH} 5.5$ after exposure to the AMF for $1 \mathrm{~min}$. (b) The corresponding digital photos of the cumulative release of DOX in vitro at $24 \mathrm{~h}$. (a)

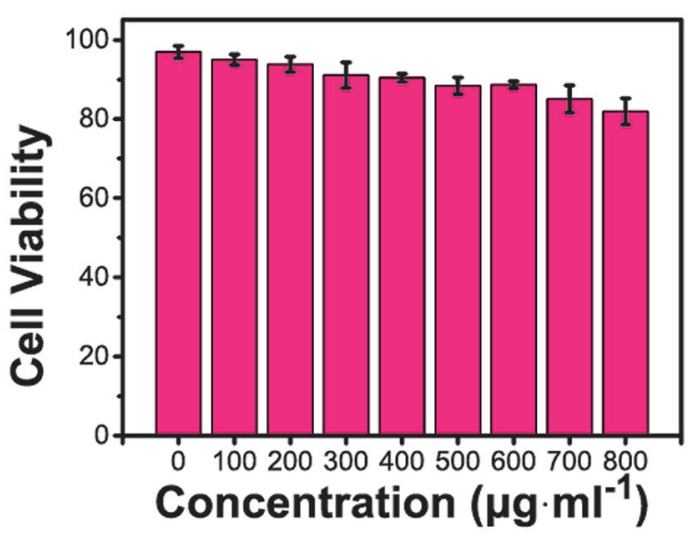

(b)

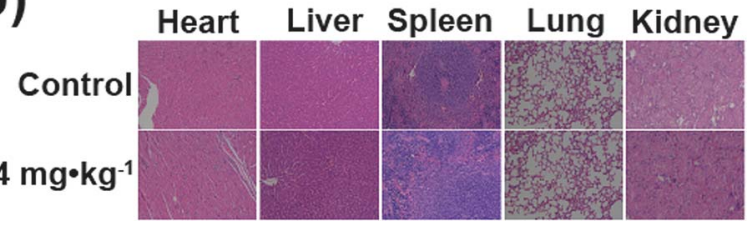

Fig. 5 (a) Cell viability-concentration histogram from the CCK8 assay for different $\mathrm{HPMC} / \mathrm{Fe}_{3} \mathrm{O}_{4}$ suspension injection dosages. (b) H\&E staining of the heart, liver, spleen, lung, and kidney of a mouse 14 days after injection of the $\mathrm{HPMC} / \mathrm{Fe}_{3} \mathrm{O}_{4}$ suspension at different concentrations $\left(0,4 \mathrm{mg} \mathrm{kg}^{-1}\right)$ (a)

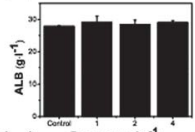

(e)

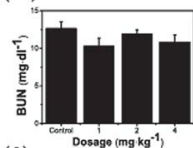

(i)

(i)

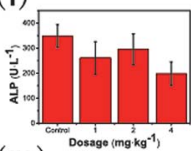

(m)

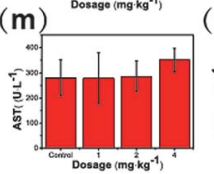

(b)

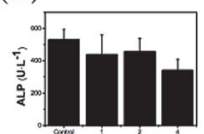

(f)

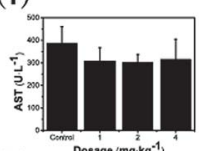

(j)

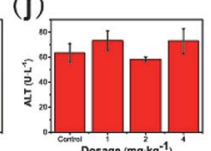

(n)

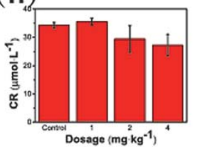

(c)

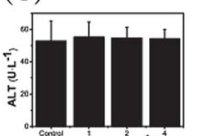

(g)

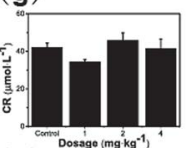

(k)

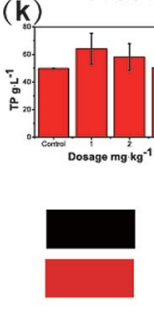

(d)

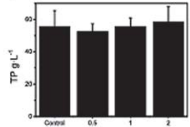

(h)

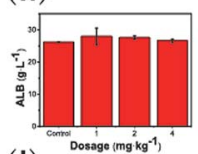

(I)

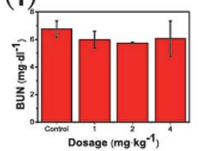

7 days after injection

14 days after injection
Fig. 6 Biochemical indexes of mice 7 or 14 days after injection of the $\mathrm{HPMC} / \mathrm{Fe}_{3} \mathrm{O}_{4}$ suspension at different concentrations.

\subsection{Ablation efficiency in the excised bovine liver}

The ablation range in excised bovine liver was macroscopically measured (Fig. 7a). Considering the larger ablation range and the smallest dosage of the injected $\mathrm{HPMC} / \mathrm{Fe}_{3} \mathrm{O}_{4}$ hydrogel, an injection dosage of $60 \mu \mathrm{L}$ with $10 \mathrm{~min}$ of heating time, which caused an ablation radius of $5 \mathrm{~mm}$, was selected for the following in vivo experiments. The macrophotographs of the excised bovine liver were captured (Fig. 7b) and show that the 
(a)

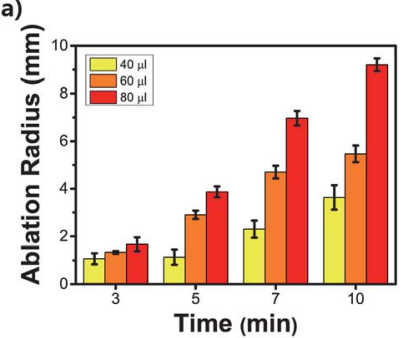

(c)

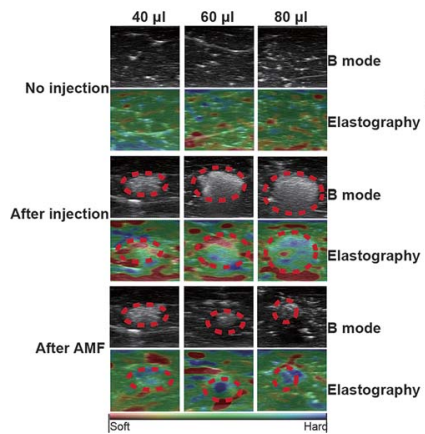

(b)

(d)
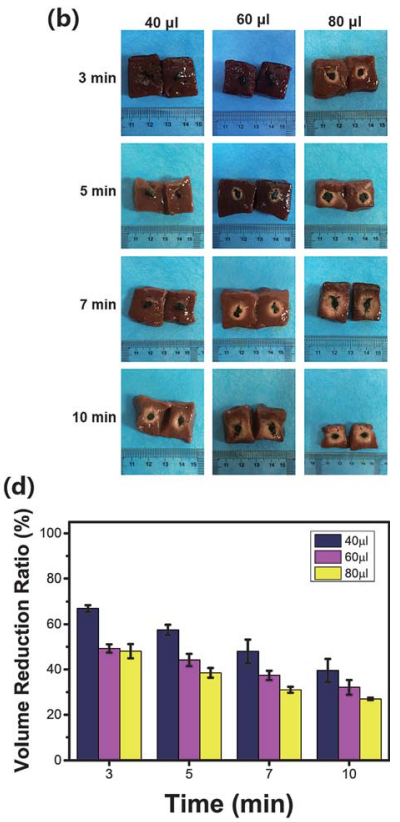

Fig. 7 (a) The ablation radius generated by $\mathrm{HPMC} / \mathrm{Fe}_{3} \mathrm{O}_{4} / \mathrm{DOX}$ in the AMF. (b) Transsection macrograph of excised bovine liver after the AMF ablation at different time points (3, 5, 7, and $10 \mathrm{~min}$ ). (c) Ultrasound elastrography and $\mathrm{B}$ mode images showing the $\mathrm{HPMC} / \mathrm{Fe}_{3} \mathrm{O}_{4}$ reduction and hardening after magnetic hyperthermia. (d) The volume reduction of different injected volumes of $\mathrm{HPMC} / \mathrm{Fe}_{3} \mathrm{O}_{4} / \mathrm{DOX}$ measured by ultrasound.

ablation range elongated with longer heating time and with higher injection dosages. The time-ablation distance curves showed increasing ablation distances with increased heating times and increased injection dosages. This can provide guidance for the appropriate heating time in the AMF and appropriate dosage for further in vivo experiments depending on the tumor size to achieve the best ablation effect without damage to normal tissue. As shown in Fig. 7c, the grey values of the magnetic hydrogel detected by ultrasound are different from normal tissue. After exposure to the AMF, the cross-sectional area of the $\mathrm{HPMC} / \mathrm{Fe}_{3} \mathrm{O}_{4} / \mathrm{DOX}$ hydrogel decreased. The volumes of the 40,60 , and $80 \mu \mathrm{L}$ injections of the magnetic hydrogel decreased after exposure to the AMF for $10 \mathrm{~min}$ (Fig. 7d). These results are not identical to the results obtained in vitro. The change in the volume of the hydrogel depends on the temperature change and the excised bovine liver contains moisture, which affects the increase in temperature. Ultrasound elastography was used to detect the phase transition. In Fig. 7c, the red area is soft while the blue area is hard. It is obvious that the $\mathrm{HPMC} / \mathrm{Fe}_{3} \mathrm{O}_{4} / \mathrm{DOX}$ hydrogel is harder than the tissue and after exposure to AMF the blue region increased in the injection area. It can be inferred that the $\mathrm{HPMC} / \mathrm{Fe}_{3} \mathrm{O}_{4} / \mathrm{DOX}$ hydrogel solidified in the tissue. However, the temperature of the material could not be directly detected because the $\mathrm{HPMC} / \mathrm{Fe}_{3} \mathrm{O}_{4} /$ DOX hydrogel was injected inside the excised bovine liver. However, the temperature was detected in the previous experiment. Therefore, the combination of ultrasound measurements and elastography may be a potential method to detect the temperature in deep tissue.

\subsection{The establishment of the $4 \mathrm{~T} 1$ mouse breast cancer xenograft model and in vivo therapeutic efficiency}

To validate the therapeutic efficacy of the $\mathrm{HPMC} / \mathrm{Fe}_{3} \mathrm{O}_{4} / \mathrm{DOX}$ hydrogel in vivo, a $4 \mathrm{~T} 1$ mouse breast cancer xenograft model was employed. The breast cancer model had been successfully established with a diameter $10 \pm 0.5 \mathrm{~mm}$ on the back near the right hind leg of nude mice. 40 tumor-bearing mice were randomly divided into the following 4 groups: mice without any treatment as a control, mice exposed to the AMF with free DOX injection in situ, mice exposed to the AMF with an intratumoral $\mathrm{HPMC} / \mathrm{Fe}_{3} \mathrm{O}_{4}$ injection and mice exposed to the AMF with an intratumoral $\mathrm{HPMC} / \mathrm{Fe}_{3} \mathrm{O}_{4} / \mathrm{DOX}$ injection. With the guidance of ultrasound, $\mathrm{HPMC} / \mathrm{Fe}_{3} \mathrm{O}_{4}$ was injected into the center of the tumor (Fig. S3a $\uparrow$ ). A thermal imager was applied to monitor the temperature changes on the surface of the tumor over time (Fig. $8 \mathrm{a}, \mathrm{b}$ and $\mathrm{S} 3 \mathrm{~b} \dagger$ ). It has been reported that tumor coagulation necrosis occurs at temperatures above $47^{\circ} \mathrm{C}$ after a few minutes of exposure. ${ }^{28,47,48}$ The temperature on the surface of the center of the tumor above the injected site increased rapidly until it reached $48 \pm 1.2{ }^{\circ} \mathrm{C}$ in $1 \mathrm{~min}$. After the hyperthermia expanded to the whole tumor surface, the temperature increased slowly to $68{ }^{\circ} \mathrm{C}$ during the remaining treatment (a)

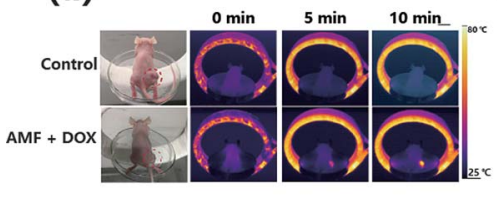

(c)

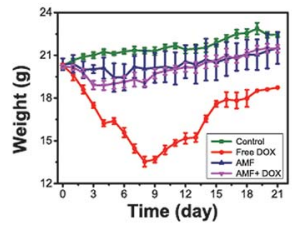

(e)

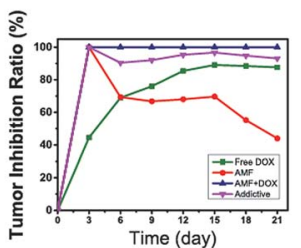

(g)
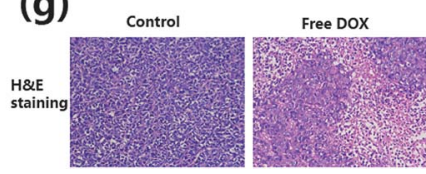

(b)

(d)
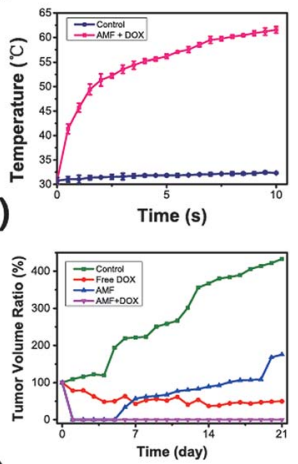

(f)

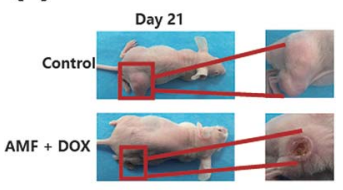

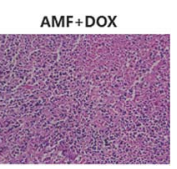

Fig. 8 (a) Infrared thermal imaging of the exposure of mice to the AMF. (b) Temperature increase curves during the exposure of mice to the AMF. (c) The weight of the mice in each group during the whole observation period. (d) The relative tumor volumes of the mice after treatment. (e) Relative tumor inhibition ratios of each group and additive tumor inhibition ratio of chemo-thermal therapy. (f) The digital photographs of mice 21 days after treatment. (g) H\&E staining of tumors in each group 3 days after treatment, showing tumor necrosis in the free DOX group, the $\mathrm{HPMC} / \mathrm{Fe}_{3} \mathrm{O}_{4}$ group and the $\mathrm{HPMC} / \mathrm{Fe}_{3} \mathrm{O}_{4} /$ DOX group, with no necrosis in the control group. 
process. In brief, the temperature of the tumor increased gently during the magnetic hyperthermia treatment process after the rapid temperature increase in the first min. This may be due to the release of liquid by the $\mathrm{HPMC} / \mathrm{Fe}_{3} \mathrm{O}_{4}$ hydrogel to control the heat rising in the tumor tissue and temperature exchanges directly between the injection site and the tumor tissue. To investigate the ablation of the tumor, on the $3^{\text {rd }}$ day after treatment, 1 mouse in each group was randomly chosen to be euthanised for tumor H\&E staining to investigate the necrosis caused by the treatment. As shown in Fig. 8g, obvious cell necrosis, such as nuclear fragmentation, pyknosis and karyolysis, was observed in the free DOX group, the AMF group and the AMF + DOX group. Normal tumor cells were observed in the free DOX group while no normal tumor cells were observed in the AMF group and the AMF + DOX group, indicating that some tumor cells still survived in the free DOX group. The macrograph (Fig. S3d $\dagger$ ) shows a normal tumor in the control group and a smaller tumor in the free DOX group than in the control group, while macroscopic ablation tissue is observed in the AMF and the AMF + DOX groups. The HPMC/ $/ \mathrm{Fe}_{3} \mathrm{O}_{4}$, which had been injected into the tumor, was also found to be gelated into a solid due to the lost water during the AMF heating process. To further demonstrate the therapeutic efficacy, the weight and the tumor volume of each mouse was measured on each day (Fig. 8c, $d$ and $\mathrm{S} 3 \mathrm{e} \dagger$ ). The tumor volume of the control group increased rapidly, with increasing weight due to the tumor growth. As the tumor grew rapidly, emaciation occurred in the control group and the weight of the mice increased. The tumor volume of mice in the free DOX group was reduced in 7 days together with weight loss, and the spine protruded outward, which suggested that the mice were not healthy due to the effects of the chemotherapy drug DOX. The mice in the free DOX group died successively from the $4^{\text {th }}$ day after treatment until 1 mouse remained on the $21^{\text {st }}$ day, emaciated and in poor spirits. However, the tumor volume in the free DOX group stopped decreasing on the $4^{\text {th }}$ day, with ongoing weight loss, indicating that unitary chemotherapy did not stop the development of the tumor and its damage the organism. It has been widely reported that DOX causes severe side effects such as acute nausea and vomiting, stomatitis, gastrointestinal disturbances, alopecia baldness and cardiotoxicity. ${ }^{49-51}$ Due to the serious side effects of DOX, only one mouse in the free DOX group survived. As shown in Fig. S3c, $\uparrow$ the survival ratio of DOX group significantly decreased, with no decrease in any other group, which indicates it is DOX that accelerates deaths of the mice. Moreover, the mice in the AMF group and in the AMF with DOX group lost little weight after the tumor ablation treatment. This illustrates the ability of the $\mathrm{HPMC} / \mathrm{Fe}_{3} \mathrm{O}_{4}$ hydrogel to diminish the toxicity of DOX, since it has been reported that the character of DOX does not change under the hyperthermia ${ }^{52}$ treatment, indicating that the treatment efficiency of DOX is retained during the magnetic hyperthermia treatment. In addition, the AMF enhanced the drug release in the tumor. In this way, the damaging effect of DOX on the normal organism has been limited, while the therapeutic efficacy has been enhanced.

Although no surviving tumor cells were observed in the section from the AMF group, 3 recurrences occurred on the $5^{\text {th }}$ day, which shows that with longer observation, single magnetic hyperthermia does not inhibit the recurrence of tumors (Fig. $8 \mathrm{~g}$ and $\mathrm{S} 3 \mathrm{e} \dagger)$. On the $21^{\text {st }}$ day, the mice in the AMF + DOX group recovered to a healthy state and there was no recurrence (Fig. $8 \mathrm{~g}$ and $\mathrm{S} 3 \mathrm{e} \dagger$ ), which indicates that chemo-magnetic hyperthermia therapy can treat tumor without recurrence and with lower DOX toxicity. In addition, the measured tumor inhibition ratio of the AMF + DOX group is much higher than that of the other groups, and significantly higher than the calculated values (additive group) after 5 days (Fig. 8e), confirming the efficiency of the chemo-thermal synergistic therapy in vivo. To investigate the health of the mice from each group, the heart, liver, spleen, lung and kidney of mice were obtained for H\&E staining. No significant differences can be observed between the normal tissue and the tissue from tumor-bearing mice, indicating that there is no tumor metastasis to the internal organs (Fig. S4 $\dagger$ ).

To summarize, free DOX reduced the tumor growth over a period time but damaged the organism and the $\mathrm{HPMC} / \mathrm{Fe}_{3} \mathrm{O}_{4}$ hydrogel with the AMF could ablate the tumor to some extent but did not prevent recurrence. Combining DOX with the magnetic hyperthermia treatment decreased the tumor recurrence with less damage to the organism.

\section{Conclusion}

In this study, an injectable $\mathrm{HPMC} / \mathrm{Fe}_{3} \mathrm{O}_{4} / \mathrm{DOX}$ hydrogel was developed and used for chemo-magnetic hyperthermia tumor therapy. The resulting $\mathrm{HPMC} / \mathrm{Fe}_{3} \mathrm{O}_{4} / \mathrm{DOX}$ hydrogel has $\mathrm{pH}$-sensitive and magnetic response capabilities with high biosafety. As shown by the preliminary results for DOX release in acidic environments and triggered by magnetic hyperthermia, these unique properties provide a significant step towards tumor therapy applications. More importantly, no tumor recurrences occurred in the chemo-thermal therapy group, while recurrences occurred in the thermal therapy group within 21 days after the magnetic hyperthermia treatment, which demonstrated the high therapeutic efficacy of chemothermal therapy. This result may be due to enhanced DOX release during magnetic hyperthermia treatment, leading to a synergistic treatment. We believe that this material combined with DOX chemotherapy could improve the therapeutic effects and promote the efficiency, controllability and safety of magnetic hyperthermia treatments, representing a step forward towards clinical applications.

\section{Ethical statement}

All animal procedures were performed in accordance with the Guidelines for Care and Use of Laboratory Animals of Shanghai Jiaotong University affiliated Shanghai sixth people's hospital and approved by the Animal Ethics Committee of the Institutional Animal Care and Use Committee (IACUC) of Shanghai Jiaotong University affiliated Shanghai sixth people's hospital.

\section{Conflicts of interest}

There are no conflicts to declare. 


\section{Acknowledgements}

The authors thank Prof. Yaopeng Zhang from DongHua University for help with this study. We acknowledge financial support from 973 project (2014CB744500), the National Science Foundation for Distinguished Young Scholars (NO. 81425014), the National Natural Science of China (NO. 81720108023, 31630026), and Shanghai Key Discipline of Medical Imaging (2017ZZ02005).

\section{References}

1 L. Bildstein, C. Dubernet and P. Couvreur, Adv. Drug Delivery Rev., 2011, 63, 3-23.

2 W. Cheng, J. Nie, L. Xu, C. Liang, Y. Peng, G. Liu, T. Wang, L. Mei, L. Huang and X. Zeng, ACS Appl. Mater. Interfaces, 2017, 9(22), 18462.

3 X. Cai, X. Jia, W. Gao, K. Zhang, M. Ma, S. Wang, Y. Zheng, J. Shi and H. Chen, Adv. Funct. Mater., 2015, 25, 2520-2529.

4 S. Baek, R. K. Singh, D. Khanal, K. D. Patel, E.-J. Lee, K. W. Leong, W. Chrzanowski and H.-W. Kim, Nanoscale, 2015, 7, 14191-14216.

5 N. Desai, Clin. Cancer Res., 2006, 12, 1317-1324.

6 A. M. Kloxin, A. M. Kasko, C. N. Salinas and K. S. Anseth, Science, 2009, 324, 59-63.

7 N. Annabi, A. Tamayol, J. A. Uquillas, M. Akbari, L. E. Bertassoni, C. Cha, G. Camci-Unal, M. R. Dokmeci, N. A. Peppas and A. Khademhosseini, Adv. Mater., 2014, 26, 85-124.

8 S. Campbell, D. Maitland and T. Hoare, ACS Macro Lett., 2015, 4, 312-316.

9 E. S. Lee, Z. Gao, D. Kim, K. Park, I. C. Kwon and Y. H. Bae, J. Controlled Release, 2008, 129, 228-236.

10 I. F. Tannock and D. Rotin, Cancer Res., 1989, 49, 4373-4384.

11 M. Stubbs, P. M. Mcsheehy, J. R. Griffiths and C. L. Bashford, Mol. Med. Today, 2000, 6, 15.

12 E. S. Lee, K. T. Oh, D. Kim, Y. S. Youn and Y. H. Bae, J. Controlled Release, 2007, 123, 19-26.

13 J. Liu, Y. Huang, A. Kumar, A. Tan, S. Jin, A. Mozhi and X. J. Liang, Biotechnol. Adv., 2014, 32, 693-710.

14 A. Bansal and Y. Zhang, Acc. Chem. Res., 2014, 47, 3052-3060. 15 N. A. Peppas, J. Z. Hilt, A. Khademhosseini and R. Langer, Adv. Mater., 2006, 18, 1345-1360.

16 K. F. Chu and D. E. Dupuy, Nat. Rev. Canc., 2014, 14, 199208.

17 B. Thiesen and A. Jordan, Int. J. Hyperthermia, 2009, 24, 467474.

18 J.-H. Lee, J.-t. Jang, J.-s. Choi, S. H. Moon, S.-h. Noh, J.-w. Kim, J.-G. Kim, I.-S. Kim, K. I. Park and J. Cheon, Nat. Nanotechnol., 2011, 6, 418-422.

19 F. Wang, Y. Yang, Y. Ling, J. Liu, X. Cai, X. Zhou, X. Tang, B. Liang, Y. Chen, H. Chen, D. Chen, C. Li, Z. Wang, B. Hu and Y. Zheng, Biomaterials, 2017, 128, 84-93.

20 R. Parhi, P. Suresh and S. Patnaik, J. Pharm. Invest., 2015, 45, 319-327.

21 J. Kopecek, Nature, 2002, 417, 388.

22 R. Langer and D. A. Tirrell, Nature, 2004, 428, 487.
23 P. Bourrinet, H. H. Bengele, B. Bonnemain, A. Dencausse, J. M. Idee, P. M. Jacobs and J. M. Lewis, Invest. Radiol., 2006, 41, 313.

24 S. Li, S. Lin, B. P. Daggy, H. L. Mirchandani and Y. W. Chien, Int. J. Pharm., 2003, 253, 13-22.

25 J. Siepmann and N. A. Peppas, Adv. Drug Delivery Rev., 2012, 64, 163-174.

26 R. Parhi, P. Suresh and S. Patnaik, J. Pharm. Invest., 2015, 45, 1-9.

27 M. H. Huang and M. C. Yang, Int. J. Pharm., 2008, 346, 38-46. 28 G. Paradossi, F. Cavalieri, E. Chiessi, C. Spagnoli and M. K. Cowman, J. Mater. Sci. Mater. Med., 2003, 14, 687-691.

29 R. Muralidhar, G. S. Siddalinga Swamy and P. Vijayalakshmi, Indian J. Ophthalmol., 2012, 60, 144.

30 P. Wust, B. Hildebrandt, G. Sreenivasa, B. Rau, J. Gellermann, H. Riess, R. Felix and P. M. Schlag, Lancet Oncol., 2002, 3, 487-497.

31 A. Hervault and N. T. Thanh, Nanoscale, 2014, 6, 1155311573.

32 B. Hildebrandt, P. Wust, O. Ahlers, A. Dieing, G. Sreenivasa, T. Kerner, R. Felix and H. Riess, Crit. Rev. Oncol.-Hematol., 2002, 43, 33-56.

33 B. Luo, S. Xu, W. F. Ma, W. R. Wang, S. L. Wang, J. Guo, W. L. Yang, J. H. Hu and C. C. Wang, J. Mater. Chem., 2010, 20, 7107-7113.

34 M. M. Tomayko and C. P. Reynolds, Canc. Chemother. Pharmacol., 1989, 24, 148-154.

35 D. M. Euhus, C. Hudd, M. C. Laregina and F. E. Johnson, J. Surg. Oncol., 1986, 31, 229.

36 H. Park, J. Yang, J. Lee, S. Haam, I. H. Choi and K. H. Yoo, ACS Nano, 2009, 3, 2919-2926.

37 G. M. Hahn, J. Braun and I. Harkedar, Proc. Natl. Acad. Sci. U. S. A., 1975, 72, 937.

38 M. M. Goswami, C. Dey, A. Bandyopadhyay, D. Sarkar and M. Ahir, J. Magn. Magn. Mater., 2016, 417, 376-381.

39 I. Andreu and E. Natividad, Int. J. Hyperthermia, 2013, 29, 739-751.

40 B. V. Slaughter, S. S. Khurshid, O. Z. Fisher, A. Khademhosseini and N. A. Peppas, Adv. Mater., 2009, 21, 3307.

41 N. Annabi, J. W. Nichol, X. Zhong, C. Ji, S. Koshy, A. Khademhosseini and F. Dehghani, Tissue Eng., Part B, 2010, 16, 371.

$42 \mathrm{~J} . \mathrm{Li}$ and D. J. Mooney, Nat. Rev. Mater., 2016, 1, 16071.

43 N. K. Verma, M. P. Purohit, D. Equbal, N. Dhiman, A. Singh, A. K. Kar, J. Shankar, S. Tehlan and S. Patnaik, Bioconjugate Chem., 2016, 27, 2605-2619.

44 E. R. Gillies and J. M. J. Fréchet, Bioconjugate Chem., 2005, 16, 361-368.

45 N. Zhang, X. Cai, W. Gao, R. Wang, C. Xu, Y. Yao, L. Hao, D. Sheng, H. Chen and Z. Wang, Theranostics, 2016, 6, 404.

46 S. E. Bianchi, V. W. Angeli, K. C. B. d. Souza, D. d. S. Miron, G. d. A. Carvalho, V. d. Santos and R. N. Brandalise, Mater. Res., 2011, 14, 166-171.

47 P. Bruners, T. Braunschweig, M. Hodenius, H. Pietsch, T. Penzkofer, M. Baumann, R. W. Günther, T. Schmitz- 
Rode and A. H. Mahnken, Cardiovasc. Intervent. Radiol., 2010, 33, 127-134.

48 P. R. Stauffer and S. N. Goldberg, Int. J. Hyperthermia, 2004, 20, 671-677.

49 C. Carvalho, R. X. Santos, S. Cardoso, S. Correia, P. J. Oliveira, M. S. Santos and P. I. Moreira, Curr. Med. Chem., 2009, 16, 3267.
50 J. Liu, D. Tu, J. Dancey, L. Reyno, K. I. Pritchard, J. Pater and L. K. Seymour, Breast Canc. Res. Treat., 2006, 100, 263-271.

51 B. Kalyanaraman, J. Joseph, S. Kalivendi, S. Wang, E. Konorev and S. Kotamraju, Mol. Cell. Biochem., 2002, 234-235, 119.

52 W. Gao, Y. Zheng, R. Wang, H. Chen, X. Cai, G. Lu, L. Chu, C. Xu, N. Zhang, Z. Wang, H. Ran, P. Li, C. Yang, Z. Mei and J. Song, Acta Biomater., 2016, 29, 298-306. 